\title{
The demography of desert Australia
}

\author{
Dominic Brown ${ }^{\mathrm{A}}$, John Taylor $^{\mathrm{B}, \mathrm{C}}$ and Martin Bell ${ }^{\mathrm{A}}$ \\ ASchool of Geography, Planning and Architecture, University of Queensland, St Lucia, \\ Brisbane, Qld 4072, Australia. \\ ${ }^{\mathrm{B} C e n t r e ~ f o r ~ A b o r i g i n a l ~ E c o n o m i c ~ P o l i c y ~ R e s e a r c h, ~ T h e ~ A u s t r a l i a n ~ N a t i o n a l ~ U n i v e r s i t y, ~}$ \\ Canberra, ACT 0200, Australia. \\ ${ }^{\mathrm{C}}$ Corresponding author. Email: j.taylor@anu.edu.au
}

\begin{abstract}
In recent years, with the formation of organisations such as the Desert Knowledge Cooperative Research Centre, social science interest in the Australian desert has re-surfaced with a research emphasis that is focused on creating sustainable futures for the region. One consequence of this is a demand for detailed demographic information to allow an assessment of different quanta of need in social and economic policy, and for assessment of the impact of these in environmental policy. However, demographic analysis on human populations in the desert to date has attracted very little research attention. In this paper we begin to address this lack of analysis by focusing on the populations, both aboriginal and non-aboriginal, of the arid and semi-arid zones of Australia. We extend earlier analysis by including for the first time demographic information on the semi-arid as well as the arid zone to establish the spatial pattern of population growth within the whole desert area drawing attention to the resulting settlement structure as an outcome of prevailing social, cultural and economic conditions. By examining population structure and demographic components of population change we also present for the first time population projections for the semi-arid zone and, therefore, in combination with the arid zone, for the entire Australian desert. All of this provides a basis for considering social and economic policy implications and the nature of underlying processes that drive change in this region.
\end{abstract}

Additional keywords: arid, indigenous, population, projections, semi-arid.

\section{Introduction}

Using the broadest definition, deserts occupy one quarter of the earth's land surface and are inhabited by just over 500 million people $(7.5 \%$ of the total), although most of these live in semi-arid fringes (UNEP 2006). Although exceptions increasingly exist, deserts are consequently synonymous with low population density. This is no more so than in Australia where the notion of limits to settlement beyond an ecumene has been a long-standing issue in public debate. The most celebrated episode in this regard occurred during the years of economic boosterism following World War I. This surrounded the scientific work of Griffith Taylor (1926), who debunked populist notions of 'Australia unlimited' with a cautious (though, in hindsight, clearly accurate) prediction of an Australian national population of 19-20 million by the turn of the century (Powell 1988). We note that this was largely based on his estimates of severe spatial limits on land use and settlement owing to the low rainfall regime that prevails across the vast desert area of the continent (Taylor 1926).

In recent years, social science interest in the Australian desert has re-surfaced through the formation of the Desert Knowledge Cooperative Research Centre (DKCRC), though with a research emphasis now that is less concerned with limits to settlement and more focused on creating sustainable social, economic and environmental futures for the region as it exists. The area encompassed by this research effort incorporates both the arid and semi-arid zones, with the latter typically associated around the world with higher population densities based on pastoral and rangeland activities (Grove 1977; Heathcote 1983). One consequence is a demand for detailed demographic information for each of these zones to allow an assessment of different quanta of need in social and economic policy, and for assessment of the impact of these in environmental policy.

Although ecology ultimately defines the Australian desert, deserts may be marked by unique social, economic and cultural characteristics. In Australia there is a significant presence of aboriginal populations, comprising more than one fifth of the arid zone population and up to $12 \%$ in the semi-arid zone. However, away from the major towns and service centres, aboriginal peoples often constitute the majority. They share the desert with largely peripatetic non-aboriginal residents drawn to the region primarily for the purposes of employment in one of the few mainstays of the regional economy - mining, pastoralism, tourism and service delivery. This limited economic base reflects the extreme remoteness from urban metropolitan Australia and produces a settlement pattern that is characterised by a few widely-separated regional towns and a broad rural base with most social and economic linkages externally-focused, except among aboriginal peoples. 
Although the desert occupies $68 \%$ of the Australian landmass it accounts for just $3 \%$ of the national population. Partly because of the sparsity of settlement that this creates, desert regions have attracted very little population analysis - a situation that is not unique to Australia. Indeed, from a perusal of international science and social science bibliographies it is remarkable to discover that in the wake of the 2006 International Year of Deserts and Desertification the vast bulk of research papers on the population of deserts across the world continue to refer to flora and fauna, and not to human populations. Other than the joint efforts of the United Nations Educational, Scientific and Cultural Organisation (UNESCO), the International Geographic Union (IGU) and the International Union for the Scientific Study of Population (IUSSP), who focused their attention in 1994 on population and environment in arid regions (Clarke and Noin 1998), together with related demographic analyses in Jordan (Findlay 1998; Findlay and Maani 1999), the only other explicit focus on the human demography of arid lands occurred around the same time in Australia in relation to emerging urban issues (Parkes 1984; Parkes et al. 1985). More recently the focus has moved to remote areas identified in the accessibility/remoteness index of Australia (ARIA) (Hugo 2006) and differential aboriginal and non-aboriginal population dynamics (Taylor 2003). This latter study provides a useful starting point for the present paper. Our intention is to extend this earlier analysis by including for the first time demographic information on the semi-arid zone identified in line with conventional subclassifications of arid regions (Meigs 1952). As noted, most the world's desert populations reside in semi-arid areas where human pressures on ecosystems are often acute, and Australia is no exception. In this way, we establish the spatial pattern of population growth within the whole desert area drawing attention to the resulting settlement structure as an outcome of prevailing social, cultural and economic conditions. By examining demographic components of population change we also present for the first time population projections for the semi-arid zone and, therefore, in combination with the arid zone, for the entire Australian desert. All of this provides a basis for considering social and economic policy implications and the nature of underlying processes that drive change.

\section{Delimiting the desert}

A prerequisite for regional demographic analysis is a clear demarcation of spatial boundaries - in this instance, the arid and semi-arid zones. The arid zone is easily identified using the Interim Biogeographical Regionalisation for Australia (IBRA) (Hutchinson et al. 2005). This is an integrated classification of both biotic and abiotic variation derived from a landscapebased approach to classifying the land surface, including attributes of climate, geomorphology, landform, lithology, and characteristic flora and fauna. On this basis, the IBRA identifies the arid zone as a single entity. However, it does not delimit a single semi-arid zone. To distinguish the latter, we apply the $500 \mathrm{~mm}$ rainfall isohyet as the outer limit from the arid zone in line with standard global classification (Grove 1977). The resulting boundaries are shown in Fig. 1. Of course, this is not the only method than can be employed to delimit these ecological zones. For example the ratio of evaporation to precipitation (aridity index) (UNEP 1997) has been extensively used, whereas the Australian Collaborative Rangelands Information System (ACRIS) have extended the Australian Bureau of Agricultural and Resource Economics (ABARE) classification, although again the latter does not differentiate the arid and semi-arid zones. However, the differences in these delimitations, especially when combining them into administrative zones, is minimal and, thus, does not greatly affect our derived population counts.

For demographic analysis, the key question is whether these boundaries agree with those of administrative units for which population data are collected - a question common to all analyses based on user-defined regions that combine different boundary types (Rees et al. 2004). Accordingly, a range of methods have been developed to overcome this problem including best fit, proportional weighting and dasymetric estimation (Blake et al. 2000; Reibel and Bufalino 2005). In the present analysis best fit methods are applied to populationweighted centroids of statistical local areas (SLAs) (ABS 2003). SLAs were chosen as the building block for this approach as they are the smallest geographical unit to which census migration data are coded. The solution is shown superimposed on ecological zones in Fig. 1. Fortunately, the selected Australian Bureau of Statistics (ABS) boundaries were consistent at the margins between 1996 and 2001 and this permits a discussion of the spatial pattern of population change for that period.

\section{Population data issues}

It is not possible to discuss desert populations without first clarifying the use of the terms 'aboriginal' and 'indigenous'. The latter term is used to encompass both aboriginal and Torres Strait Islander peoples in Australia, of whom all desert dwellers are aboriginal. However, population accounts data (and population estimates) from the ABS are only available for the category 'indigenous population', which combines persons who identify in ABS collections as aboriginal, Torres Strait Islander, or both of these. Thus, in discussing issues generally in the introductory sections and conclusions to this paper, we refer to desert aboriginal people, whereas in the data sections of the paper we mostly use the official term 'indigenous'.

Practical and methodological issues arise with regard to the availability and quality of appropriate demographic data because of the need to disaggregate indigenous and nonindigenous populations. Although the ABS produces annual population estimates, these are only available by indigenous status in census years. Annual registrations of births and deaths, on the other hand, do include an indigenous status identifier but the coverage reliability of this is questionable (Brown 2005). Other annual demographic data collections, such as those pertaining to migration, do not report indigenous status. Consequently, this leaves the quinquennial census and population estimates calculated for census years as the main sources of data on population size, composition, and migration, and births and deaths information can be derived by cumulating vital registrations over a 5-year period. 


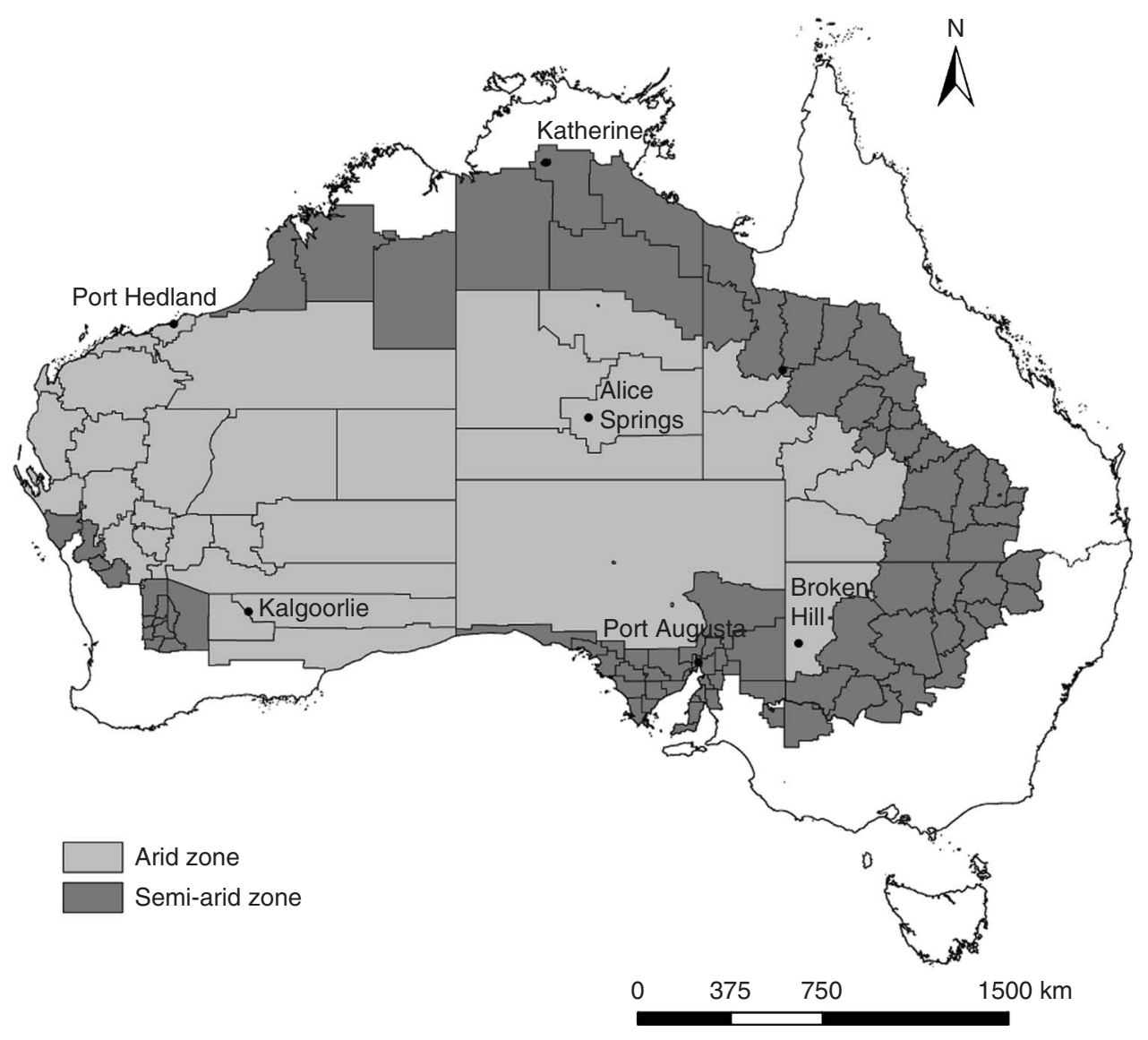

Fig. 1. Statistical local areas (SLAs) in arid and semi-arid Australia (ABS 2001a).

It should be noted that all of these data items are subject to variable errors of under-reporting and that the impact of this is more pronounced because of the small population base. For example, recording of demographic variables in many Australian SLAs, especially in the two arid zones, is rendered difficult by large geographic size, small and dispersed populations (Howe 1999). Frequent short-term population movement and high population turnover also complicate this (Storey 2001; Taylor and Bell 2004; Bell and Brown 2005). In addition, Kinfu and Taylor (2005) have noted possible under-reporting of births data in some arid areas that may be due to misreporting of usual place of residence. As a consequence there continue to be concerns about the accuracy of demographic information pertaining to all populations in these regions, but especially to indigenous populations. In the meantime, analysis must inevitably proceed with data that are available, though clearly due care is required to establish the most reliable parameters of change.

\section{Size of the desert population}

The arid and semi-arid zones cover most of the Australian continent, and account for 3.5 million $\mathrm{km}^{2}$ ( $45 \%$ of the landmass) and 1.79 million $\mathrm{km}^{2}$ (23\% of the landmass), respectively. The arid zone population of 176506 in 2001, thus, produces a very low overall population density of just 0.05 persons per $\mathrm{km}^{2}$, while the semi-arid zone population of 406990 converts to 0.23 persons per $\mathrm{km}^{2}$. These calculations include several locally-significant population centres, such as Alice Springs, Mt Isa, Port Hedland and Kalgoorlie, where population densities are considerably greater than the arid zone average. However, it should be noted that the resident desert population is highly mobile, and regional towns form a destination for many temporary movers, thus, blurring distinctions between town and country populations. It is also true that the desert caters for large numbers of temporary visitors from elsewhere in Australia, such as tourists and fly-in/fly-out (FIFO) workers, whose usual place of residence is either elsewhere in Australia or overseas. Estimation of these populations is increasingly recognised as an important component of any comprehensive demography of the region, raising crucial issues regarding the selection of appropriate population measures for use in service planning and delivery (Bell and Brown 2005, Bell and Brown 2006). Their importance is clear in the 2001 census where the place of enumeration count for the arid zone was $17 \%$ higher than the usual resident count - 145146 compared with 123538 .

Given the spatial extent of the two biogeographic zones encompassing parts of Western Australia, the Northern Territory, Queensland, New South Wales and South Australia, a crossjurisdictional context for considering social, economic, cultural and environmental issues in relation to deserts is 
created (Table 1). At the same time, the degree to which the desert and its population form a part of each jurisdiction varies. Thus, more than half of the arid zone population is located in Western Australia alone (Table 1) and most of this population $(84 \%)$ is non-indigenous drawn to the area by employment opportunities in mining towns such as Newman and Tom Price, Kalgoorlie and Port Hedland. The other main concentration of arid zone population (and the largest indigenous population) is in the Northern Territory focused mostly on Alice Springs and outlying indigenous settlements. Elsewhere, most of the remaining arid zone population is located in New South Wales (Broken Hill), followed by South Australia from the Flinders Ranges northwards. Once again, Indigenous peoples here (located largely in the Anangu Pitjantjara lands) are outnumbered regionally by non-indigenous residents largely due to mining settlement at places like Olympic Dam, Roxby Downs and Coober Pedy. Queensland has by far the lowest arid zone population located mostly on large pastoral properties.

The semi-arid geography is very different. Both indigenous and non-indigenous populations in semi-arid areas are most numerous in Western Australia, New South Wales, Queensland and South Australia (Table 1). Aside from Western Australia, New South Wales and South Australia in particular stand out as having substantial semi-arid populations (particularly non-indigenous). For the latter, these are focused largely on the agricultural areas of the Eyre and Yorke Peninsula. In contrast, the indigenous and nonindigenous population of semi-arid Northern Territory is lower than its arid zone.

Spatially, then, both the size and distribution of indigenous and non-indigenous resident populations varies substantially across the two zones. However, the degree to which this is so is distorted by the concentration of non-indigenous population in a handful of larger regional and mining settlements as well as in agricultural parts of the semi-arid zone. A more detailed examination of population distribution at the SLA-level reveals that the indigenous population contributes more than $25 \%$ of the total population across much of the desert area (Fig. 2).

\section{Settlement pattern}

With the given prevailing low population densities, the arid and semi-arid zones coincide very closely with the 'very remote' and 'remote' components of ARIA (Hugo 2006). This classification has long structural roots and is evident in the historic distinction between 'colonial' and 'settled' Australia (Rowley 1971), that recognised much higher proportions of aboriginal people in 'colonial' areas and the somewhat different manner of their incorporation into wider social and economic structures. Indeed, away from the larger mining towns and service centres of the desert, it was, and still is, possible to talk of aboriginal 'domains' in the sense that aboriginal people and their settlements and institutions predominate.

This sense of an aboriginal domain in desert Australia has been strengthened since the 1970 s by a substantial transfer of land back to aboriginal ownership and stakeholder interest across the desert region, with the prospect of more to come through further land purchase and native title claims (Pollack 2001). Such land transfers form an important element of the post-productivist transition in Australia's rangelands (Holmes 2002), with newly recognised land values often based outside the market economy, being more culturally-focused. One manifestation of such values has been the emergence of a distinct settlement structure on aboriginal lands involving the formation of numerous, dispersed, small, and discrete aboriginal settlements (outstations) across the desert. Thus, in 2001 , only $28 \%$ of the resident indigenous population of the arid zone was located in the four major urban centres of the arid zone - Alice Springs, Port Hedland, Kalgoorlie and Broken

Table 1. Arid and semi-arid zone indigenous and non-indigenous estimated resident population by state and territory jurisdiction, 2001

Source: ABS customised tables

\begin{tabular}{|c|c|c|c|c|c|c|}
\hline & $\begin{array}{l}\text { Indigenous } \\
\qquad(n)\end{array}$ & $\begin{array}{c}\text { Non-indigenous } \\
(n)\end{array}$ & $\begin{array}{c}\text { Total } \\
(n)\end{array}$ & $\begin{array}{c}\text { Indigenous } \\
(\%)\end{array}$ & $\begin{array}{c}\text { Non-indigenous } \\
(\%)\end{array}$ & $\begin{array}{c}\text { Total } \\
(\%)\end{array}$ \\
\hline \multicolumn{7}{|c|}{ Arid } \\
\hline NSW & 1278 & 20674 & 21952 & 5.8 & 94.2 & 100.0 \\
\hline Qld & 491 & 2441 & 2932 & 16.7 & 83.3 & 100.0 \\
\hline SA & 3395 & 10088 & 13483 & 25.1 & 74.9 & 100.0 \\
\hline WA & 14909 & 79352 & 94261 & 15.8 & 84.2 & 100.0 \\
\hline NT & 17530 & 26348 & 43878 & 40.0 & 60.0 & 100.0 \\
\hline Total & 37603 & 138903 & 176506 & 21.3 & 78.7 & 100.0 \\
\hline \multicolumn{7}{|c|}{ Semi-arid } \\
\hline NSW & 14439 & 74207 & 88646 & 16.3 & 83.7 & 100 \\
\hline Vic. & 1187 & 48429 & 49616 & 2.4 & 97.6 & 100 \\
\hline Qld & 9568 & 57982 & 67550 & 14.2 & 85.8 & 100 \\
\hline SA & 6686 & 132413 & 139099 & 4.8 & 95.2 & 100 \\
\hline WA & 13866 & 28781 & 42647 & 32.5 & 67.5 & 100 \\
\hline NT & 9150 & 9265 & 18415 & 49.7 & 50.3 & 100 \\
\hline Total & 54896 & 351077 & 405973 & 13.5 & 86.5 & 100 \\
\hline
\end{tabular}




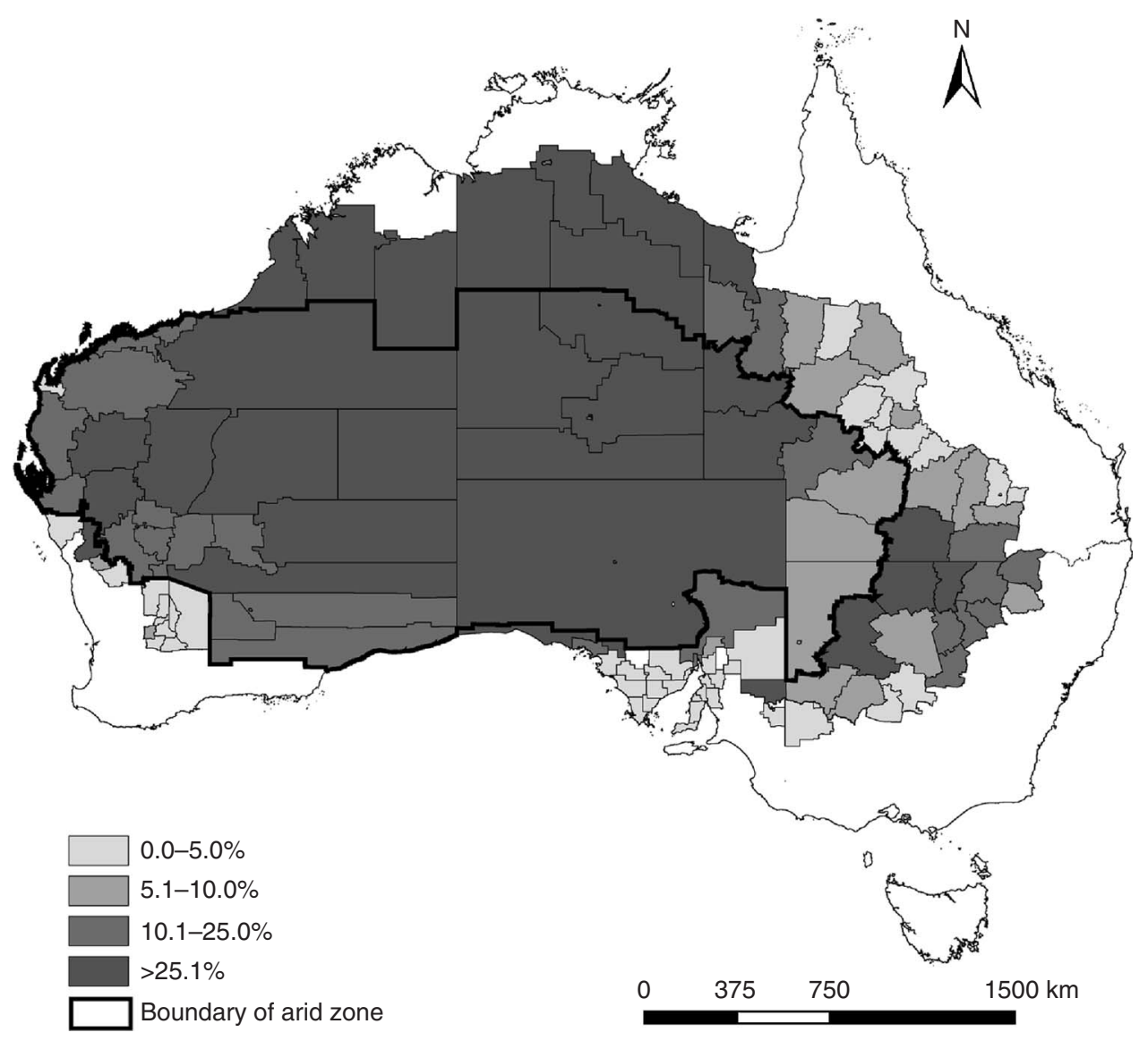

Fig. 2. Indigenous percent of total statistical local area (SLA) population, 2001 (ABS customised tables).

Hill - compared with as much as $57 \%$ of non-indigenous residents, who are concentrated in this way because of employment opportunities. Consequently, away from the larger mining towns and service centres, indigenous people are increasingly the majority and there is every reason to expect this to continue given current population dynamics.

The combination of these forces for concentration and dispersal produces a rank-size distribution of settlements that varies substantially from one that is log normal (Zipf 1949). In the arid zone, for example, the system is dominated by a few mining and service towns of roughly equivalent size ( $\sim 3000$ persons) such as Kalgoorlie, Alice Springs and Broken Hill at the top of the hierarchy, below which is a tier of $\sim 15$ small towns between 1000 and 3500 persons with a similar economic base. From this level down there are progressively fewer smaller settlements than predicted against the log normal rank size distribution with 144 localities of between 30 and 1000 persons, and 270 very small places of less than 30 persons (Taylor et al. 2006). These represent discrete indigenous communities identified by the ABS (2001b) Community Housing and Infrastructure Needs Survey (CHINS). Although this distribution excludes small pastoral settlements owing to a lack of data, these are relatively few in the arid zone and their inclusion would be unlikely to alter the observed rank size curve.
Further, there is a lack of discrete indigenous settlements in the arid zone that have achieved urban status ( $>1000$ persons) as this stands in contrast to the situation in the semi arid and savanna regions of the Northern Territory and Queensland (Taylor 2006). There is some indication that this reflects possible limits to growth for desert communities that may be linked to issues of sociability and community cohesiveness (Fletcher 1990). In central Australia, for example, the pattern of settlement growth generally observed over the past two decades has been of settlements reaching a population ceiling (typically between 250 and 500 people) at which point they either stabilise or fragment spatially (Taylor 2001) with population growth accommodated by the formation of new smaller settlements or by out-migration to the major desert towns and beyond (Taylor 2006). What available data do not reveal, however, and what would be important to know, is the extent to which individuals who occupy small desert settlements also spend periods of temporary residence in regional centres, as indicated, for example, by survey work and census analysis in the town of Alice Springs and elsewhere (Taylor 1998; Foster et al. 2005).

\section{Population change 1996-2001}

The population of desert Australia experienced very modest growth of just 1\% between 1996 and 2001, although this was 
entirely due to an increase in the indigenous population of just over 10000 since the non-indigenous population decreased by 4500 . This contrast in relative growth was most evident in the arid zone where the indigenous population increased by almost $9 \%$ and non-indigenous growth was less than zero at $-3.4 \%$. By contrast, the semi-arid zone experienced positive growth in both populations, although most of this was due to much higher growth in the indigenous population (15 compared with $0.2 \%$ ) (Taylor et al. 2006).

The narrow economic base of the arid and semi-arid regions, with their heavy reliance on primary production and government spending, produces an inherent instability in population levels. Spatially this is manifest in mixed fortunes: as pastoral and agricultural areas have shared in the general drain of population from the inland towards coastal Australia (McKenzie 1994; Brown et al. 2006), mineral provinces and associated towns have both increased and decreased according to demand cycles for resource extraction. Currently, the minerals sector is experiencing a 'super cycle' of demand that should stimulate population growth in desert regions through direct and indirect employment for decades to come (Hooke 2007), although data to measure initial impacts are limited to date, and much will depend in the long run on the significance of FIFO operations (Storey 2001). Tourism and service-related industries provide an equally variable stimulus to resident population growth. The overall effect on population change is spatially diverse, and considerable difference is evident between the indigenous and non-indigenous populations.

Between 1996 and 2001, indigenous population growth was widespread across much of the arid zone, with several SLAs experiencing substantial increases in excess of $20 \%$ (Fig. $3 a$ ). By contrast, many semi-arid areas especially in central Queensland and South Australia displayed indigenous population decline. Non-indigenous population growth was restricted to central Australia and the Kimberley, with almost wholesale population decline everywhere else especially in the arid areas of Western Australia away from the Pilbara coast, and across the entire semi-arid zone (Fig. 3b).

\section{Population structure}

Aside from total population size, it is the age and sex composition of the population that best reflects the demographic outcome of regional drivers and has major implications for service delivery and related policy. We note a consistency in the age-sex structures of both indigenous and non-indigenous populations across the arid and semi-arid zones (Fig. $4 a, b$ ). Indigenous age pyramids have a relatively wide base, indicative of common high fertility, although with some indication that fertility has recently declined as the 0-4 years age groups are smaller in both cases than the older 5-9 years age groups. They also display rapid tapering of the age distribution, indicative of high and rising mortality with age. The possibility that this tapering is also due to net migration loss is refuted by intercensal migration data that show the highest net losses among younger age groups (Taylor et al. 2006).

In contrast, the non-indigenous age distributions display a relatively narrow base owing to much lower fertility rates. There is also a clear reduction in the number of non-indigenous males and females aged 10-14 to 20-24 years in both regions compared with the immediately younger and older age groups. For example there are 26257 persons aged 5-9 in the semiarid region in 2001, which decreases to 19404 persons aged 20-24 years before increasing to 24085 persons aged 25-29 years. This is distinctly different to the even tapering revealed for the indigenous population and is evidence of net migration loss, most likely associated with education and training, departure from the parental home, and search for employment. In contrast to this, the major bulge in nonindigenous populations in prime working age years is directly associated with migration into the desert for employment.

Slightly harder to discern from the population pyramids are contrasting sex ratios between the indigenous and nonindigenous populations. Indigenous sex ratios are at parity (1.00) in the arid zone and close to parity (1.02) in the semi-arid zone reflecting a high degree of gender balance. Non-indigenous ratios, however, are excessively high at 1.19 and 1.08, respectively, in the arid and semi-arid zones, indicating many more males than females in the population. However, these averages conceal considerable variation between SLAs with non-indigenous sex ratios rising as high as 2.12 in certain mining towns of Western Australia reflecting the limited occupational structure of employment opportunities in many desert locations. More research is required to identify whether this dearth of females in arid and semi-arid Australia is, indeed, one of the factors driving population decline in the region - the need to leave the area to find a partner.

\section{Components of population change}

Changes to the size and composition of the desert population derive from a combination of regional births, deaths and net migration. As indicated earlier, accurate estimation of these components is generally compromised by data of variable quality. Nonetheless, indicative parameters can be established and these are presented below.

\section{Fertility}

The fertility of indigenous women is considerably higher than that recorded for non-indigenous women, and peak childbearing age occurs earlier (Kinfu and Taylor 2005). This pattern is clearly evident in both the arid and semi-arid zones (Fig. 5). The net result of these age specific fertility rates (births per 1000 females in that age group) is to produce total fertility rates (TFRs, or the average number of children born per woman) that are considerably higher for indigenous women in each of the zones -2.45 and 2.80 for indigenous females in the arid and semi-arid zones, respectively, compared with 1.96 and 2.10 for the non-indigenous. Part of the explanation for higher population growth rates in the semi-arid part of the desert are reflected in these results, with sustained higher fertility among both indigenous and nonindigenous females beyond age 20. Accordingly the prospects for natural increase are higher in the semi arid zone.

It is important to note that these indigenous TFRs reported are likely to be minimum outcomes as they represent indigenous women's fertility only and do not include indigenous births to non-indigenous mothers. They are also based 


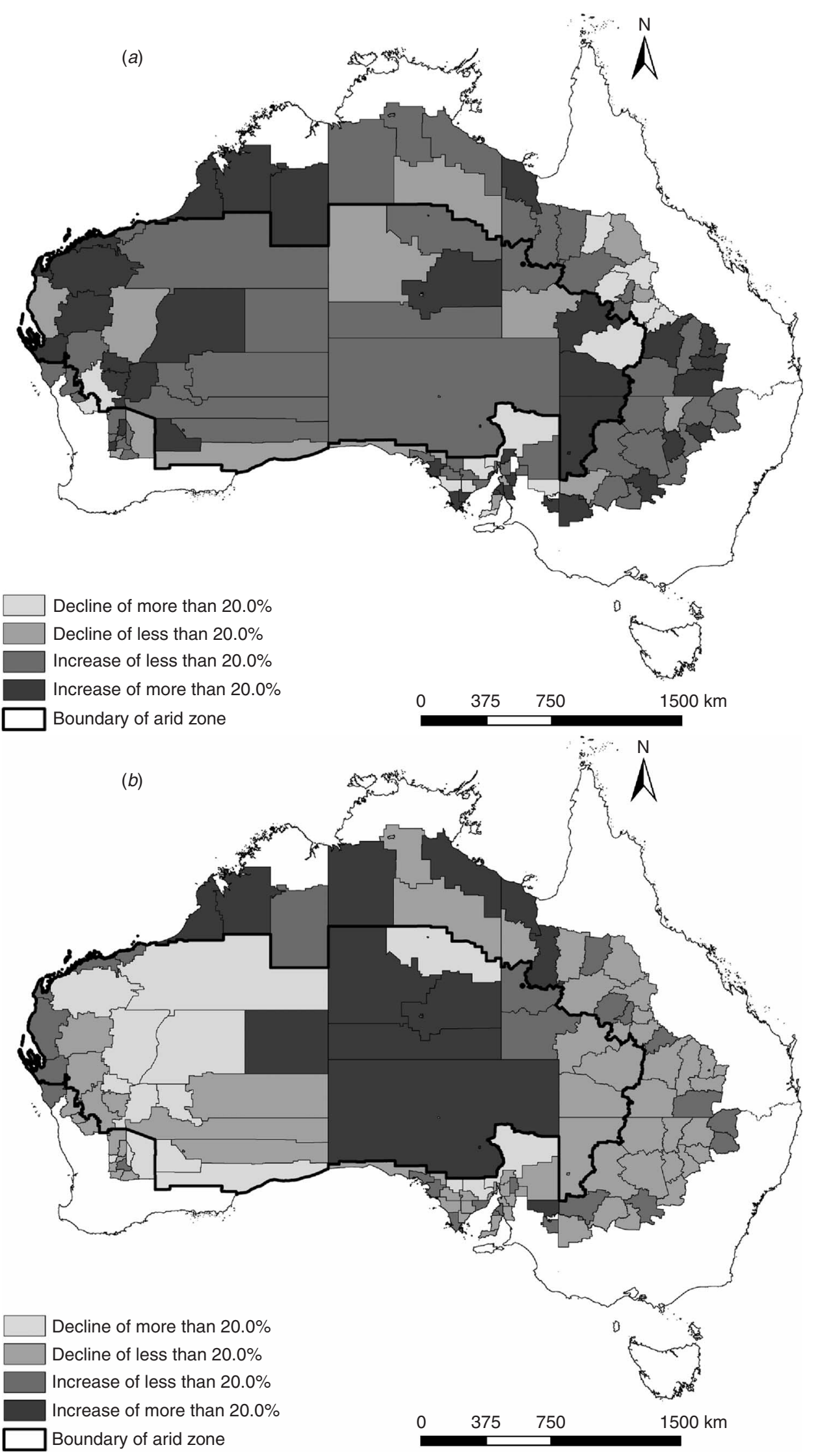

Fig. 3. Population change 1996-2001: (a) indigenous, (b) non-indigenous (ABS customised tables). 

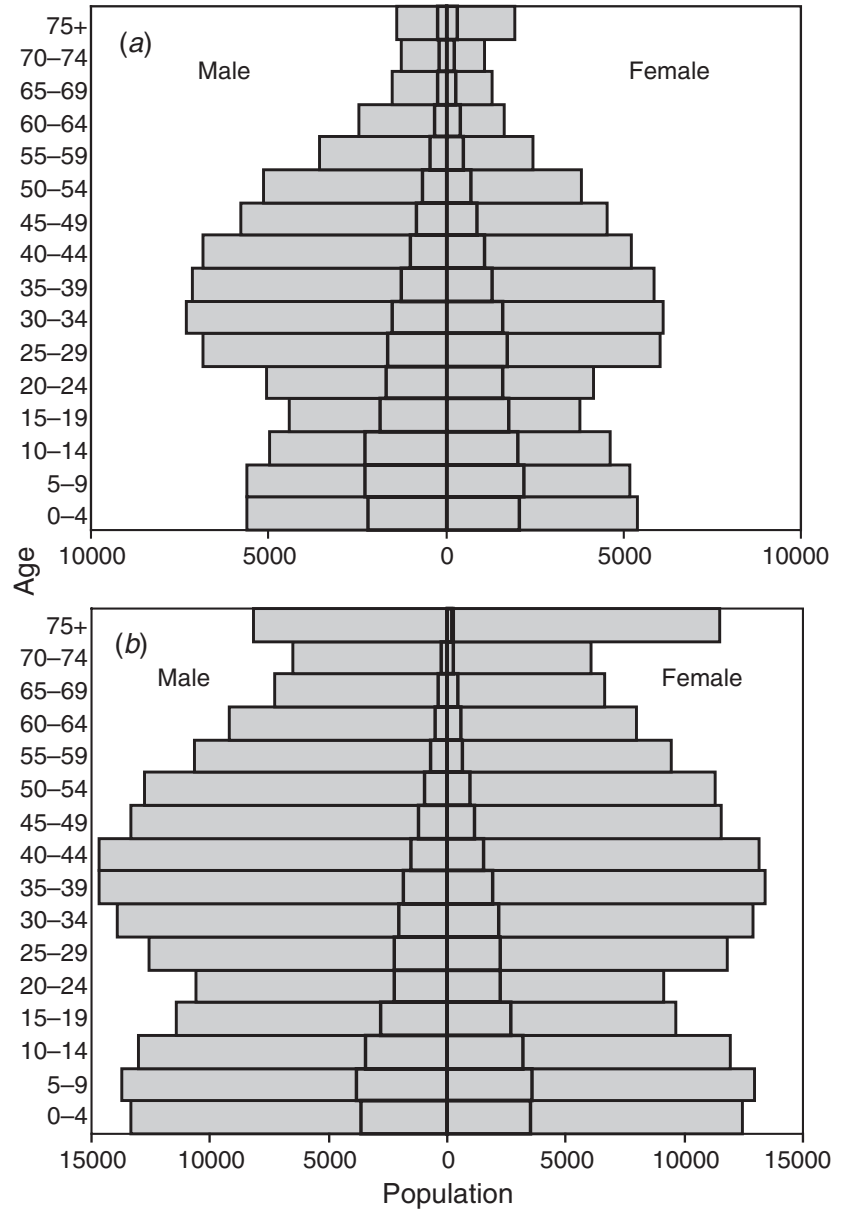

$\square$ Non-indigenous $\square$ Indigenous

Fig. 4. Indigenous and non-indigenous age distributions, 2001: (a) arid zone, (b) semi-arid zone (ABS customised tables).

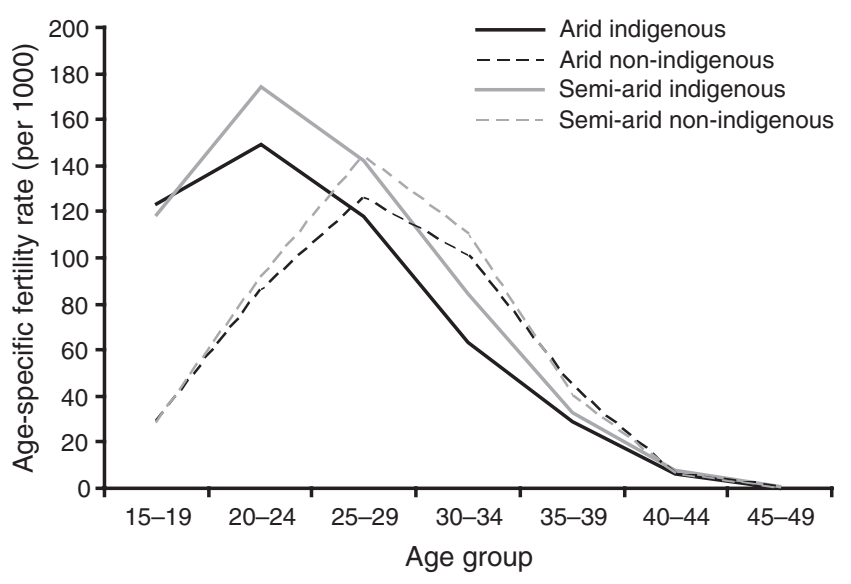

Fig. 5. Indigenous and non-indigenous age specific fertility rates (ASFR), 2001 (ABS customised tables).

on registered births as opposed to births drawn from midwives' collection (such as those available in Western Australia) that have been shown to produce higher numbers of indigenous births and higher TFRs than registered births (Taylor and Scambary 2005).

\section{Mortality}

An attempt was made to construct a life table for the two arid zones using registered deaths data by indigenous status. However, the available data were not sufficiently robust for this purpose. Even when averaged over several years, the basic problem is one of too few numbers, especially in younger age groups, with a correspondingly disproportionate effect on overall life expectancy outcomes. To overcome this, a proxy of mortality differentials in the desert can be applied using indigenous and non-indigenous age- and sex-specific death rates (deaths per 1000 persons in that age-sex group) for the Northern Territory, on the assumption that these are the officially available rates most likely to apply across the arid and semi-arid zones. The relative rates are shown in Fig. 6.

Indigenous death rates in the Northern Territory are clearly higher at all ages for both males and females, although much more so for males. Against this background, the overall pattern by age is similar for both populations with a fall from relatively high infant mortality to low mortality among 5-14 year olds. Thereafter mortality rates steadily rise, especially among young adult indigenous males, although substantial gaps when compared with the rest of the population become evident for both indigenous males and females by age 30. Despite subsequent convergence with age, this gap remains considerable throughout the adult years. Thus, from a regional demographic perspective, the net consequence of this survival gap is to produce a relative brake on indigenous population growth, although there will be substantial potential momentum for growth in the event of any improvement in indigenous mortality.

\section{Internal migration}

Migration is the most troublesome of the components of population change because it can substantially impact on regional population growth yet reliable data are difficult to acquire. In terms of the impact of migrant flows, the key observation from 2001 Census data is that both the arid and semi-arid zones lost indigenous and non-indigenous population to the rest of

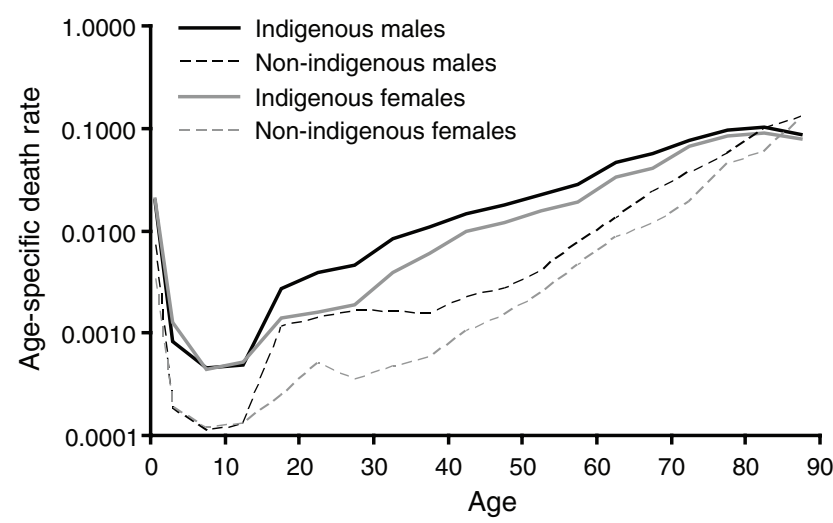

Fig. 6. Indigenous and non-indigenous age specific death rates (ASDR) by sex, 1997-2001 (T. Wilson, pers. comm.). 
Australia. Between 1996 and 2001 almost 116000 nonindigenous residents of the desert moved out to other parts of Australia and 75000 moved into the desert producing a net loss of 41000 . Equivalent figures for the indigenous population were 8500 out and 5500 in with a net loss of 3000. More important, though, for assessing relative demographic impact, is the intensity of these migration flows; here it is significant that the rate of non-indigenous net migration loss from the desert was more than twice that of the indigenous population. Considerable differences were also evident within the desert with the non-indigenous net loss occurring in the arid zone at almost five times the rate for the indigenous population, and semi-arid rates were similar for the two populations (Taylor et al. 2006).

This considerable difference in the intensity of net migration loss from the arid zone underlines the key demographic reason why the indigenous share of total desert population continues to rise. It also reflects the very different factors that influence mobility among the two broad segments of the desert population. Some clue to these is provided by an examination of the differential age and sex structure migration rates, drawn from the 2001 census, as shown for the arid and semi-arid zone populations in Fig. $7 a, b$.

In each case, non-indigenous movement rates exceed indigenous rates at all ages (and especially in the arid zone), except to a limited extent at older ages. Furthermore, the gap in rates is often substantial, most notably in the prime

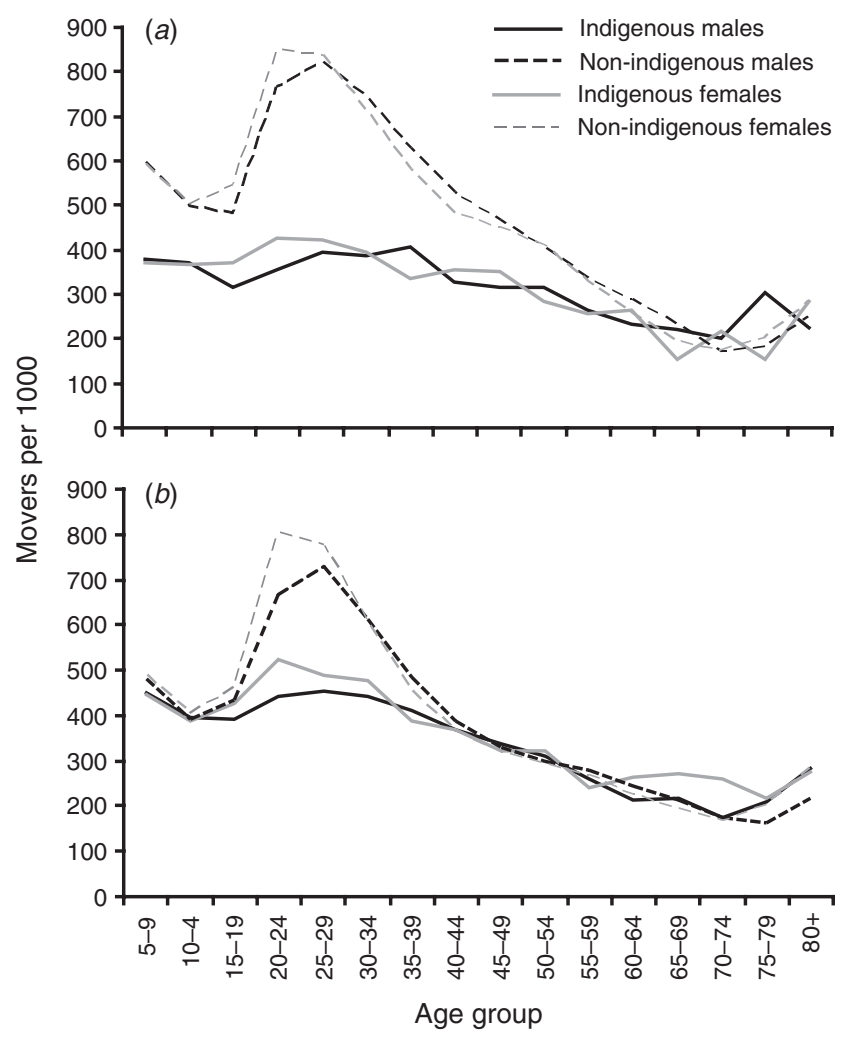

Fig. 7. Indigenous and non-indigenous propensities to move by age and sex, 1996-2001: (a) arid zone, (b) semi-arid zone (ABS census 2001 customised tables). movement ages between 15 and 35 years. If there is any variation in this pattern at all it is found in the semi-arid zone where the gap between indigenous and non-indigenous rates is somewhat narrower largely because indigenous mobility rates are generally higher than in the arid zone.

For the population as a whole, this peak in the age profile of migration in the young adult age range has been firmly linked to the combined influence of life cycle events including departure from the parental home, the start of tertiary education and training, entry into the labour force, and the establishment of independent living arrangements (Bell 1995). In the desert regions, high movement rates for the non-indigenous population aged between 15 and 35 years are firmly linked to employment in key sectors such as mining and service industries. Although broad agreement in this patterning of migration by age suggests that similar influences also bear on the indigenous young adult population, the much flatter profile of indigenous mobility also suggests that such drivers are far weaker. This no doubt reflects a combination of cultural and socioeconomic factors. For example, much lower labour force participation has been observed in the desert for indigenous people at ages when job search and job mobility are primary factors in population movement for the rest of the population (Taylor and Scambary 2005). Also, the establishment of independent living arrangements is likely to be less of a stimulus for migration among young indigenous adults in a cultural setting that places emphasis on maintaining extended kinship ties. In any case, there is often a shortage of available housing to accommodate new household formation, and this, combined with high dependence on rental housing, creates an additional constraint on migration (Foster et al. 2005).

The lack of census-recorded indigenous mobility in desert areas has been noted before (Taylor and Bell 1996). It contrasts markedly with evidence from ethnographic and survey studies that reveal very high levels of indigenous mobility in the desert (Young and Doohan 1989; Warchivker et al. 2000; Foster et al. 2005) with circular movements extending at times across the entire arid zone (Peterson 2004). At one level, this discrepancy highlights methodological issues concerning the limited value of fixed-period census measures of population movement in situations where circulation is the predominant form of mobility. At another level, it accurately reflects the relative lack of permanent residential relocation among indigenous people in the desert who are mobile, but not migrant. Unlike the majority of non-indigenous residents of the desert who originate from elsewhere in Australia, most indigenous people are located within kin-defined territories that demarcate a field of spatial interaction involving multiple residential sites (Young and Doohan 1989; Young 1990; Memmott et al. 2006). Invariably, this includes a regional centre (such as Alice Springs, Port Augusta, Mt Isa, Kalgoorlie, Port Hedland, and Broken Hill) as well as a network of indigenous townships and outstations. For the most part, this pattern of interaction ensures that indigenous mobility is mostly between locations within the desert rather than between the desert and elsewhere.

However, even where indigenous migration is recorded by the census, there are added interpretive difficulties in desert regions, 
in particular in relation to the pattern of net migration by age. Thus, in the arid zone, the rate of indigenous net migration loss is relatively low, but this is recorded overwhelmingly among younger people from age 5-19 years. Among older parental ages a mix of net loss and gain is evident with no clear pattern from one age group to the next. In the semi-arid zone, the rate of net loss is highest among 5-9 year olds and then recedes progressively with age such that net gains are recorded among older adults over 50 years. Both of these patterns are difficult to interpret with little adherence to social reality, especially in terms of household or family migration. At best, they may reflect migration associated with education as many indigenous children from remote areas attend schools in more settled areas - either as boarders or by staying with relatives; what may be occurring is that usual residence counts are reflecting the site of educational attendance rather than the home base. Whatever the case, considerable doubt surrounds the accuracy of indigenous net migration data.

\section{Population projections 2006-21}

To date, policy development in desert regions has typically been reactive to needs as they become revealed, as opposed to being proactive in seeking to anticipate and plan for expected future requirements for infrastructure, programs, and services a practice that is standard procedure in metropolitan Australia. For example, state planning authorities routinely develop future scenarios and often seek budgetary allocations on the basis of anticipated needs in major cities. A key element in this process is the production of small-area population projections or forecasts. Although the ABS provides official projections of state and territory and SLA populations, the individual states and territories, in turn, also produce regional and local area projections, often down to the local government area level (Bell 1992). For these purposes a standard cohort-component methodology is generally applied.

Anticipation of planning requirements is made more difficult in the desert because of boom and bust cycles in the regional economy plus the fact that the low population base can result in substantial swings in population size. Ideally, population projections for a region such as the Australian desert that experiences major shocks to its regional economy would attempt to account for these impacts using input-output techniques and simple demographic-economic impact forecasting (Phibbs 1989). However, these require whole-ofregion data input, especially in regard to workforce demand and composition (for example, in terms of construction-phase workforces and FIFO employment), and these sorts of data are simply not readily available. As for the indigenous desert population, relative detachment from the mainstream economy renders such demographic-economic impact methodologies less applicable. In both cases, then, a standard cohort-component projection methodology is best adopted, although with two points of caution. First, it is widely accepted, and supported by empirical evidence, that the accuracy of projections diminishes with the length of the projection horizon (Bell 1992). Second, it is well established that projections for large populations are more reliable than those for small populations (Keyfitz 1981).
Partly, for the above reasons, official projections of indigenous populations in Australia have only ever been produced for large geographic areas (states and territories) and typically are only ever prepared for much shorter time periods ( $\sim 10$ years) compared with the 20-year, 50-year and even 100-year projections often applied to the general population (ABS 2001c, 2005). Consequently, meaningful discussion of likely future demographic outcomes in the desert requires the separate calculation of indigenous population projections using SLA-level components data cumulated for desert zones (Taylor et al. 2006).

As for the non-indigenous component of the population, these are derived as a residual of the indigenous projections from existing projections of the total desert population. Basically, projections for the total population for each SLA in the country exist for the period 1999-2019 in an ABS series developed for the Commonwealth Department of Health and Ageing in 2000 using 1996 census-derived estimates and assumptions about fertility, mortality and net inter-regional migration for the total population. These were updated by the ABS to produce a revised set of projections for the period 2002-22 (Taylor et al. 2006) and the indigenous projections were subtracted from these revised data to produce a set of non-indigenous estimates.

The main drawback in this methodology is that the assumptions underlying the development of estimates for the indigenous and total populations are inevitably quite different, and so the creation of a residual (non-indigenous) population in the manner described above is statistically problematic. Ideally, projection of a 'non-indigenous' population would be guided by its own unique underlying assumptions, but this is made difficult by a lack of appropriate data for key components such as mortality. In the meantime, an ability to consider the likely changes in indigenous and non-indigenous desert populations remains crucial to future planning and policy formation, and so the residual method of estimation is retained with the proviso that any conclusions drawn are constrained by this methodology.

In constructing indigenous population projections, information from the components of change analysis were incorporated using the following assumptions:

(1) fertility: age specific fertility rates based on SLA-level registered births averaged over 1996-2001 for each zone and held constant;

(2) mortality: Northern Territory experimental survival ratios 1999-2001 held constant across both desert zones; and

(3) migration: given the problems identified above regarding net migration, the main projection sets this to zero at all ages. However, a sensitivity analysis is provided by also applying observed age-specific net rates for the period 1996-2001 and holding these constant.

\section{Projection results}

On the basis of the main run indigenous projection, the outcomes for the indigenous and non-indigenous populations are quite different. The indigenous population is projected to grow substantially in both zones, but especially in the semi-arid zone, but the non-indigenous population is projected to decline in both (Table 2). Thus, while the non-indigenous pattern of 
Table 2. Projected change in indigenous and non-indigenous population by biogeographic zone, 2006-2021

Source: ABS customised tables and own calculations

\begin{tabular}{lcccc}
\hline & 2006 & 2021 & Net change & \% Change \\
\hline Arid & 39840 & 47402 & 7562 & 18.98 \\
Semi-arid & 59290 & 74571 & 15281 & 25.77 \\
Total & 99130 & 121973 & 22843 & 23.04 \\
& \multicolumn{5}{c}{ Non-indigenous } \\
Arid & 135171 & 124775 & -10396 & -7.69 \\
Semi-arid & 349268 & 334579 & -14689 & -4.21 \\
Total & 484439 & 459354 & -25085 & -5.18 \\
\hline
\end{tabular}

projected growth is in line with the experience of many parts of non-metropolitan Australia in recent years (ABS 2007), indigenous population growth continues to run counter to this. One consequence, then, is an anticipated rise in the indigenous share of the desert population from an estimated $22.8 \%$ in 2006 to $27.5 \%$ in 2021 in the arid zone, and from 14.5 to $18.2 \%$ in the semi-arid zone. This increase is diminished substantially if observed indigenous net migration rates are allowed to apply in the projections as this slows the rate of indigenous growth. Under this assumption, the increase in the indigenous share of population in the arid zone rises to $25 \%$, but in the semi-arid zone it rises just one percentage point from the 2006 estimate, to $15 \%$.

It is useful to consider these predicted changes in demographic composition in terms of age groups that typically form the target of social policy initiatives, at least as far as the 5-year classification allows. These include the infant and pre-school years (0-4 years), the years of compulsory schooling (5-14 years using 5-year age data), the years of school-to-work transition (15-24 years), the years of family formation and employment (25-44 years), the years of family dissolution (45-64 years), and an aged category of those over 65 years.

The effects of population momentum and overall ageing are clearly visible in all these tables. The sheer weight of such momentum inherent in the original populations of young adult and middle-aged people is manifest in the growth of older age numbers by 2021 . Taking the indigenous population of the arid zone first (Table 3; Fig. 8a), the effects of population momentum and overall ageing are clearly visible with growth evident in all age groups but the highest percentage (and absolute) increase among those aged 45-64 years (3030 persons, or 54\%) and the population of working-age from $25-44$ years also increases substantially by $22 \%$. In contrast, growth among those of school-age and the elderly is projected to be relatively low at $274(3 \%)$ and $541(39 \%)$, respectively.

Projections of the non-indigenous population in the arid zone produce a quite different outcome as the only age groups projected to increase are those over 45 years (Table 3 ; Fig. 8b). Almost all of this increase is expected among those aged 65 years and over whose numbers are expected to increase by over $8000(81 \%)$, whereas all age groups below 45 years undergo decline. If these indigenous and nonindigenous projections were to eventuate the combined effect on regional age composition would be to create a greater emphasis on the population of working age.

Similar changes in age composition are projected for the semi-arid zone (Table 4; Fig. 9a, b). For the indigenous population those aged 45-64 years show the greatest percentage increase $(50 \%)$, however the population aged 25-44 shows the largest absolute increase (5908). For the non-indigenous population, growth only occurs in the oldest ages, with age groups under 45 years all showing decline of $15-24 \%$ or $5400-14700$ in absolute terms. Although these outcomes are substantially modified if the alternate indigenous net migration assumptions are applied, the basic pattern of overall ageing with indigenous growth and non-indigenous decline holds.

\section{Policy implications of desert demography}

Aboriginal people have by far the longest and most enduring presence in the Australian desert. It is equally true that, aside from the initial upheavals and demographic impacts of sustained contact with Europeans and subsequent movement into the desert of non-aboriginal peoples that commenced in the late nineteenth century, the period since the 1970s has seen the most significant shifts in desert demography (Holmes 2002; Taylor 2003). This has resulted from unprecedented growth in the aboriginal population combined with highly unstable non-aboriginal population levels owing to the vagaries of a regional economy that is heavily dependent on

Table 3. Absolute and percent change in the size of social policy target groups: non-indigenous and indigenous populations of the arid zone, 2006-2021

Source: ABS customised tables and own calculations

\begin{tabular}{|c|c|c|c|c|c|c|c|c|}
\hline \multirow[t]{2}{*}{ Age group } & \multicolumn{4}{|c|}{ Non-indigenous } & \multicolumn{4}{|c|}{ Indigenous } \\
\hline & 2006 & 2021 & Net change & $\%$ Change & 2006 & 2021 & Net change & $\%$ Change \\
\hline $0-4$ & 9906 & 7367 & -2539 & -25.63 & 4105 & 4821 & 716 & 17.45 \\
\hline $5-14$ & 18426 & 12889 & -5537 & -30.05 & 8776 & 9050 & 274 & 3.12 \\
\hline $15-24$ & 15742 & 11468 & -4274 & -27.15 & 7900 & 8267 & 367 & 4.65 \\
\hline $25-44$ & 46793 & 39287 & -7506 & -16.04 & 12095 & 14728 & 2633 & 21.77 \\
\hline $45-64$ & 34148 & 35350 & 1203 & 3.52 & 5593 & 8624 & 3030 & 54.18 \\
\hline $65+$ & 10157 & 18414 & 8258 & 81.30 & 1370 & 1912 & 541 & 39.51 \\
\hline Total & 135171 & 124775 & -10396 & -7.69 & 39840 & 47402 & 7562 & 18.98 \\
\hline
\end{tabular}



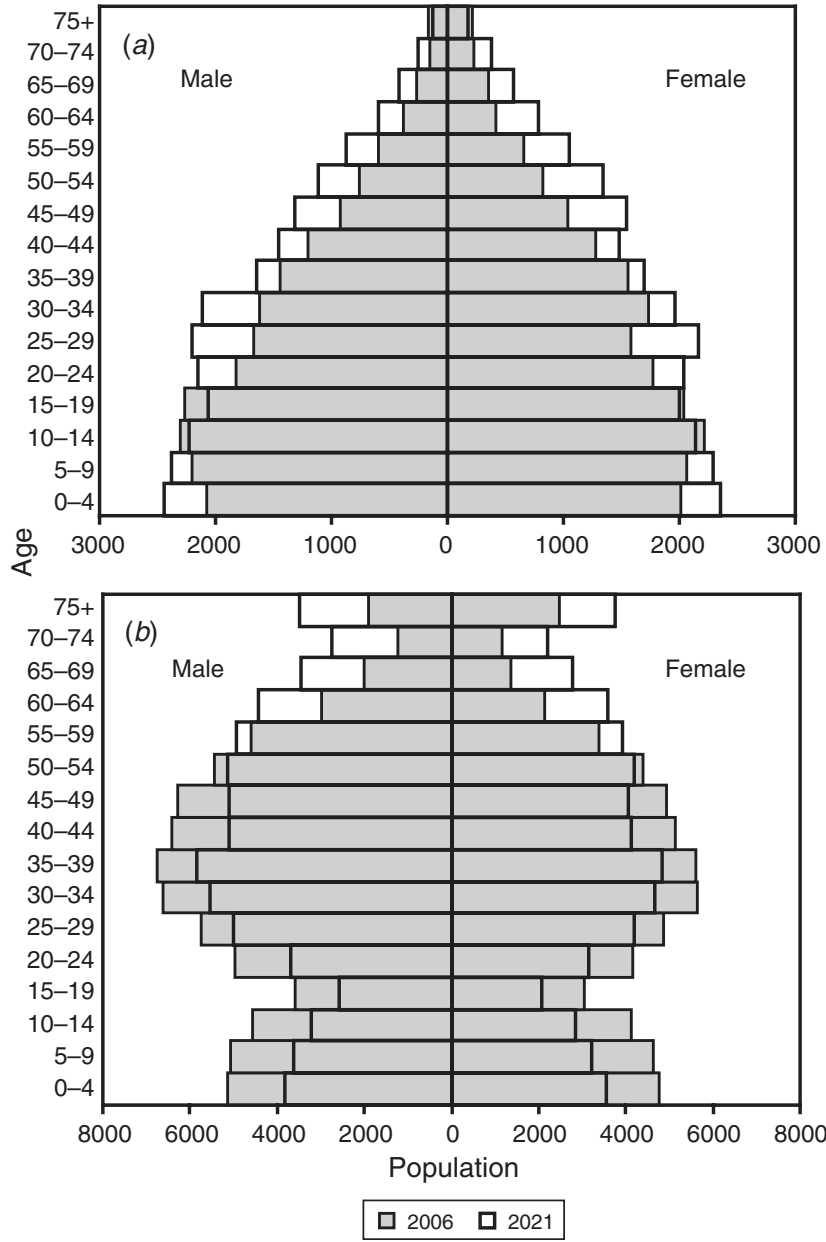

Fig. 8. Age pyramids for the population of the arid zone, 2006 and 2021: (a) indigenous, (b) non-indigenous (ABS customised tables and own calculations).

commodity prices for primary products. This same period has also brought a new contributor to regional demography with a marked increase in temporary visitation to desert regions through greatly expanded tourism. The result is a population that at any one time includes large numbers of non-residents thereby adding to service requirements, but also increasing economies of scale.
For aboriginal populations of the desert, vulnerabilities abound. Despite being traditional (and contemporary) owners of much of arid and savanna Australia, aboriginal peoples continue to exist mostly on the margins of the regional economy. Levels of labour force participation are low [certainly net of Community Development Employment Projects (CDEP) scheme employment], and access to many services is curtailed by large distances, poor communications, and low population densities that constrain local market demand. Above all, continuing high mortality remains a potent measure of basic insecurity. Despite efforts to improve aboriginal census counts and vital registration, difficulties remain in establishing even basic demographic parameters owing to inconsistencies in data, and simple estimation of aboriginal numbers and distribution is made problematic by virtue of chronic intra-regional mobility.

Against these provisos, we confidently project relatively high growth for the aboriginal population over the next 15 years. Indeed, in the arid zone, we project that this will provide the only growth. Numerically, the focus of this aboriginal growth will be at younger ages; proportionally, it will increasingly occur at older ages. In combination, these expanding cohorts present major challenges for social and economic policy. The basic implication is a need for accelerated provision of social services and infrastructure as well as enhanced economic participation just to maintain the status quo in socioeconomic status.

For non-aboriginal populations, the key characteristic of recent times has been substantial net migration loss, with more or less equal numbers moving out of the arid and semi-arid zones, but with much greater demographic impact in the arid zone due to higher rates. Compounding this is high turnover of the non-aboriginal population due to migration in and out of the desert (often to and from state capitals). Such turnover is strongly age-specific and tied to life course events with most in-movement occurring in younger working-age groups. This overall sense of impermanence is enhanced by the large number of tourist visitors who constitute a significant share of the desert population present at any one time, although with strong seasonal variation. Also, from an economic base perspective, limited horizontal integration and emphasis on single industry operations are reflected in very high sex ratios which add to distortions in regional demography.

Instabilities in the non-aboriginal population mean that major questions surround the actual size of current (and

Table 4. Absolute and per cent change in the size of social policy target groups: non-indigenous and indigenous populations of the semi-arid zone, 2006-2021

Source: ABS customised tables and own calculations

\begin{tabular}{lccccrrrr}
\hline \multirow{2}{*}{ Age group } & \multicolumn{4}{c}{ Non-indigenous } & & \multicolumn{3}{c}{ Indigenous } \\
& 2006 & 2021 & Net change & \% Change & 2006 & 2021 & Net change & \% Change \\
\hline $0-4$ & 21933 & 16511 & -5422 & -24.72 & 6603 & 8810 & 2207 & 33.42 \\
$5-14$ & 47776 & 33753 & -14024 & -29.35 & 14406 & 15602 & 1197 & 8.31 \\
$15-24$ & 38922 & 30744 & -8177 & -21.01 & 11919 & 13527 & 1607 & 13.48 \\
$25-44$ & 97048 & 82311 & -14737 & -15.19 & 16373 & 22281 & 5908 & 36.08 \\
$45-64$ & 93430 & 96603 & 3173 & 3.40 & 7792 & 11752 & 3960 & 50.83 \\
$65+$ & 50159 & 74656 & 24497 & 48.84 & 2197 & 2600 & 403 & 18.32 \\
Total & 349268 & 334579 & -14689 & -4.21 & 59290 & 74571 & 15281 & 25.77 \\
\hline
\end{tabular}



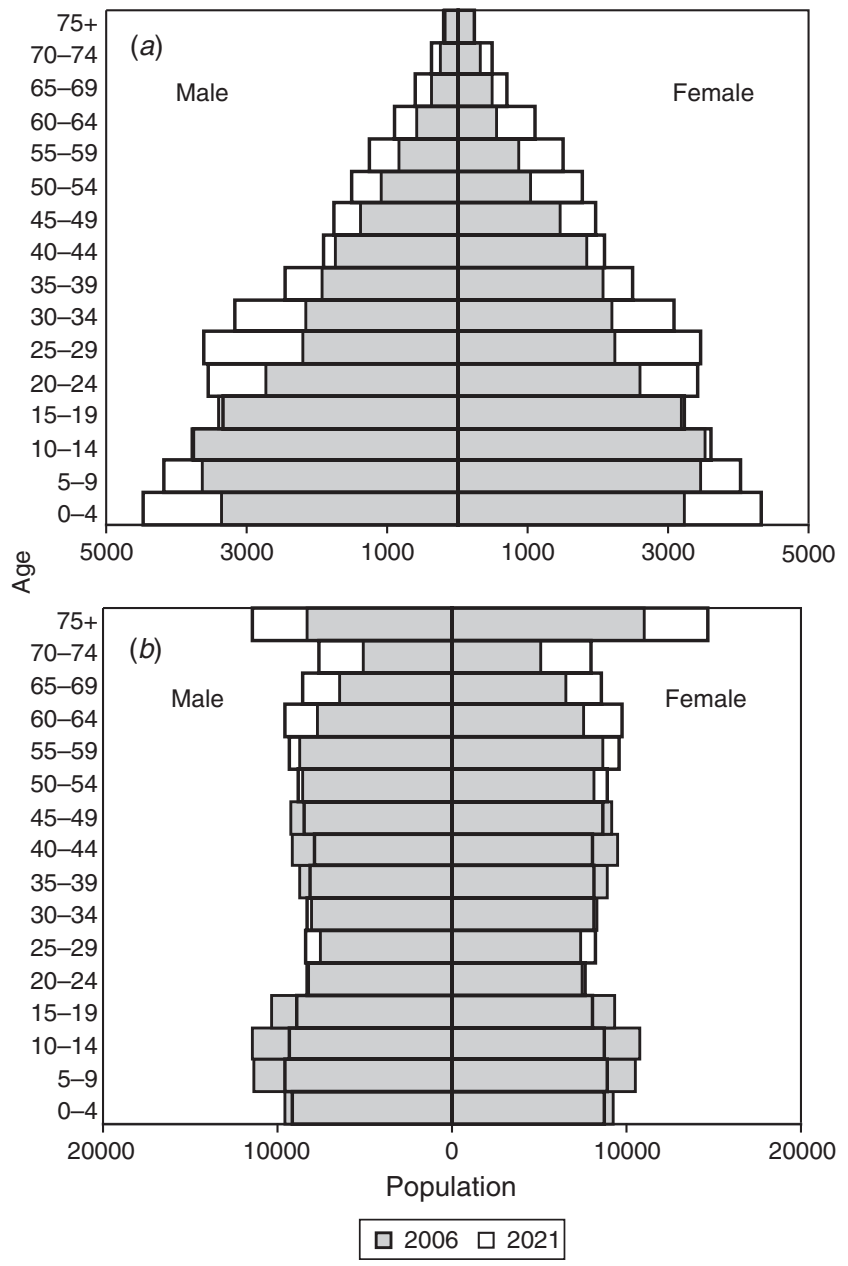

Fig. 9. Age pyramids for the population of the semi-arid zone, 2006 and 2021: (a) indigenous, $(b)$ non-indigenous (ABS customised tables and own calculations).

projected) numbers. The primary variable here is labour demand (as dictated mostly by mining and related developments), as the size and composition of associated workforces in terms of construction-phase, FIFO, and resident components, especially in regions of economic boom such as the Pilbara (Taylor and Scambary 2005) and potentially the South Australian interior, are difficult to establish. Once again, the difficulty of calibrating temporary visitors on an annual basis simply adds to this uncertainty.

Overall, demographic outcomes in the desert reflect social, economic, and cultural drivers that, in combination, are unique to the region. Overall, demographic outcomes in the desert reflect a distinct combination of social, economic and cultural drivers, some internal and some external to the region. Primary among the latter is the influence of settlement inertia in Australia with manifest strong preference and rationale for residence in coastal metropolitan areas and their hinterlands. This results in low densities in the interior and high interregional migration. It also reflects the structure of the national space-economy with opportunities in the desert constricted by the limited composition of market demand. At the same time, within the desert, continued attachment of aboriginal people to traditional lands increases dispersion of the desert population as well as the level of intra-regional mobility. It is also true that low aboriginal socio-economic status has demographic consequences reflected mostly in continued high mortality. This results in low densities in the interior and high inter-regional migration. It also reflects the structure of the national space-economy with opportunities in the desert constricted by the limited composition of market demand. At the same time, continued attachment of aboriginal people to traditional lands increases dispersion of the desert population as well as the level of intra-regional mobility. It is also true that low aboriginal socio-economic status has demographic consequences reflected mostly in continued high mortality.

All of these outcomes place special demands on public policy-how to accommodate (often literally) a growing aboriginal population that is widely dispersed and economically marginalised? How to generate economies of scale? How to arrest or manage non-aboriginal population decline? How to manage explosive, localised, population growth? How to service mobile populations? How to capitalise on expanding visitor numbers? How to manage the environmental consequences? Although many of these issues present immediate challenges, the message from this focus on population dynamics in desert Australia is a need for forward planning of policy requirements. This need is heightened by demographic uncertainties generated by the two main current drivers of social and economic change in remote Australia the super-cycle of minerals demand, and the Australian Government's moves to mainstream aboriginal populations embodied symbolically, though not exclusively, in the national emergency response to child abuse in remote Northern Territory communities (Altman and Hinkson 2007). Anticipating the demographic implications of each of these presents major research challenges.

\section{Acknowledgements}

The work reported in this publication was supported by funding from the Australian Government Cooperative Research Centres Program through the Desert Knowledge CRC; the views expressed herein do not necessarily represent the views of Desert Knowledge CRC or its participants.

\section{References}

ABS (2001a). Australian Standard Geographical Classification, 2001. Catalogue No. 1216.0, released 1 July 2001. Australian Bureau of Statistics, Canberra.

ABS (2001b). Housing and Infrastructure in Aboriginal and Torres Strait Islander Communities, Australia, 2001. Catalogue No. 4710.0, released March 2001. Australian Bureau of Statistics, Canberra.

ABS (2001c). Population Projections Northern Territory 1999-2021. Catalogue No. 3222.7, released 25 July 2001. Australian Bureau of Statistics, Canberra. Available at: www.ausstats.abs.gov.au/ausstats/ subscriber.nsf/0/6FE818DDDF5292C5CA256A940000A303/\$File/ 32227_1999\%20to\%202021.pdf (accessed 27 August 2007).

ABS (2003). Australian Standard Geographical Classification. Catalogue No. 4713.0, released 26 September 2003. Australian Bureau of Statistics, Canberra. Available at: www.ausstats.abs.gov.au/ausstats/subscriber.nsf/ 0/64C4EA55CC860D53CA256DAD0005F913/\$File/12160_2003.pdf (accessed 27 August 2007). 
ABS (2005). Population Projections Australia 2004 to 2101. Catalogue No. 3222.0, released 29 November 2005. Australian Bureau of Statistics, Canberra. Available at: www.ausstats.abs.gov.au/ausstats/subscriber.nsf/ 0/73D26920772F929ECA25718C001518FB/\$File/32220 2004\%20to \%202101reissue.pdf (accessed 27 August 2007).

ABS (2007). Regional Population Growth, Australia, 1996 to 2006. Catalogue No. 3218.0, released 27 July 2007. Australian Bureau of Statistics, Canberra. Available at: www.ausstats.abs.gov.au/ausstats/subscriber.nsf/ 0/C70AD2A06FB3A80CCA2573210018E2B2/\$File/32180 1996\% 20to\%202006.pdf (accessed 27 August 2007).

Altman, J. C., and Hinkson, M. (2007). 'Coercive Reconciliation: Stabilise, Normalise, Exit aboriginal Australia.' (Arena Publications: Melbourne.)

Bell, M. (1992). 'Demographic Projections and Forecasts in Australia: a Directory and Digest.' (Australian Government Publishing Service: Canberra.)

Bell, M. (1995). 'Internal Migration in Australia, 1986-1991: Overview Report.' (Australian Government Publishing Services: Canberra.)

Bell, M., and Brown, D. (2005). The geography of temporary mobility in Australia. QCPR Discussion Paper 2005/02. Queensland Centre for Population Research, Brisbane. Available at: www.gpa.uq.edu.au/qcpr/ Homepage/discussion_papers/2005-02-geog-temp-mob.pdf (accessed 27 August 2007)

Bell, M., and Brown, D. (2006). Who are the visitors? Characteristics of temporary movers in Australia. Population, Place and Space 12, 77-92. doi: 10.1002/psp.390

Blake, M., Bell, M., and Rees, P. (2000). Creating a temporally consistent spatial framework for the analysis of interregional migration in Australia. International Journal of Population Geography 6, 155-174. doi: 10.1002/(SICI)1099-1220(200003/04)6:2<155::AID-IJPG180>3.0. $\mathrm{CO} ; 2-\mathrm{A}$

Brown, D. (2005). A comment on the Australian Bureau of Statistics' experimental method for calculating life tables for use in population estimates and projections of aboriginal and Torres Strait Islander Australians. QCPR Discussion Paper 2005/01. Queensland Centre for Population Research, Brisbane. Available at: www.gpa.uq.edu.au/qcpr/ Homepage/discussion_papers/2005-01-indig-life-tables.pdf (accessed 27 August 2007).

Brown, D., Muhidin, S., Bell, M., and Wilson, T. (2006). The structure of internal migration in Australia. QCPR Discussion Paper 2006/01. Queensland Centre for Population Research, Brisbane. Available at: www.gpa.uq.edu.au/qcpr/Homepage/discussion_papers/2006-01Structure-of-migration.pdf (accessed 27 August 2007).

Clarke, J. I., and Noin, D. (1998). 'Population and Environment in Arid Regions of the World. Man and the Biosphere Series.' (UNESCO: Paris.)

Findlay, A. M. (1998). Policy implications of population growth in arid environments. In 'Population and Environment in Arid Regions of the World, Man and the Biosphere Series'. (Eds J. I. Clarke and D. Noin.) pp. 353-362. (UNESCO: Paris.)

Findlay, A. M., and Maani, M. (1999). Development implications of demographic trends and projections for an arid region: the case of the Badia Research and Development Project area of Jordan. Applied Geography 19, 283-298. doi: 10.1016/S0143-6228(99)00010-7

Fletcher, R. (1990). Residential densities, group sizes and social stress in Australian aboriginal settlements. In: 'Hunter-gatherer Demography: Past and Present'. (Eds B. Meehan and N. White.) pp. 81-94. (University of Sydney: Sydney.)

Foster, D. E., Mitchell, J., Ulrik, J., and Williams, R. (2005). 'Population and Mobility in the Town Camps of Alice Springs.' (Desert Knowledge Cooperative Research Centre: Alice Springs.)

Grove, A. T. (1977). The geography of semi-arid lands. Philosophical Transactions of the Royal Society of London. Series B, Biological Sciences 278, 457-475. doi: 10.1098/rstb.1977.0055

Heathcote, R. L. (1983). 'The Arid Lands: their Use and Abuse.' (Longman: London.)
Holmes, J. (2002). Diversity and change in Australia's rangelands: a post-productivist transition with a difference? Transactions 27, 362-386. doi: 10.1111/1475-5661.00059

Hooke, M. (2007). National Press Club Address. Mitchell, H. Hooke, Chief Executive Officer, Minerals Council of Australia, 4 April 2007. Available at: www.minerals.org.au/ data/assets/pdf file/19549/MCA MHH_NatPressClub-040407_Revised.pdf (accessed 27 August 2007).

Howe, A. (1999). Assessing the accuracy of Australia's small area population estimates. Journal of the Australian Population Association 16, 47-65.

Hugo, G. (2006). Space, place, population and census analysis in Australia. In 'Australian Bureau of Statistics Census Analysis Conference'. pp. 36. (Australian Bureau of Statistics: Canberra.)

Hutchinson, M. F., McIntyre, S., Hobbs, R. J., Stein, J. L., Garnett, S., and Kinloch, J. (2005). Integrating a global agro-climatic classification with biological boundaries in Australia. Global Ecology and Biogeography 14, 197-212. doi: 10.1111/j.1466-822X.2005.00154.x

Keyfitz, N. (1981). The limits to population forecasting. Population and Development Review 7, 579-593. doi: 10.2307/1972799

Kinfu, Y., and Taylor, J. (2005). On the components of indigenous population change. The Australian Geographer 36, 233-255. doi: 10.1080/ 00049180500150027

McKenzie, F. (1994). 'Regional Population Decline in Australia.' (Australian Government Publishing Service: Canberra.)

Meigs, P. (1952). Arid and semi-arid climatic types of the world. In: 'Proceedings of the 8th General Assembly and 17th International Congress'. (International Geographical Union: Washington.)

Memmott, P., Long, S., and Thomson, L. (2006). 'Indigenous Mobility in Rural and Remote Australia.' (Australian Housing and Urban Research Institute: Brisbane.)

Parkes, D. N. (1984). 'Northern Australia: the Arenas of Life and Ecosystems on Half a Continent.' (Academic Press: Sydney.)

Parkes, D. N., Burnley, I. H., and Walker, S. R. (1985). 'Arid Zone Settlement in Australia: A Focus on Alice Springs.' (United Nations University Press: Tokyo.)

Peterson, N. (2004). Myth of the 'walkabout': movement in the aboriginal domain. In: 'Population Mobility and Indigenous Peoples in Australasia and North America'. (Eds J. Taylor and M. Bell.) pp. 223-238. (Routledge: London.)

Phibbs, P. (1989). Demographic-economic Impact forecasting in nonmetropolitan regions: an Australian example. In: 'Advances in Regional Demography: Information, Forecasts, Models'. (Eds P. Congdon and P. Batey.) pp. 150-164. (Belhaven Press: London.)

Pollack, D. P. (2001). Indigenous land in Australia: a quantitative assessment of indigenous landholdings in 2000. CAEPR Discussion Paper 221/2000. Centre for Aboriginal Economic Policy Research, The Australian National University, Canberra. Available at: www.dspace.anu. edu.au/bitstream/1885/41132/1/2001_DP221.pdf (accessed 27 August 2007).

Powell, J. M. (1988). 'An Historical Geography of Modern Australia: the Restive Fringe.' (Cambridge University Press: Cambridge.)

Rees, P., Norman, P., and Brown, D. (2004). A framework for progressively improving small area population estimates. Journal of the Royal Statistical Society. Series A 167, 5-36.

Reibel, M., and Bufalino, M. (2005). Street-weighted interpolation techniques for demographic count estimation in incompatible zone systems. Environment \& Planning A 37, 127-139. doi: 10.1068/a36202

Rowley, C. D. (1971). 'The Remote Aborigines.' (Australian National University Press: Canberra.)

Storey, K. (2001). Fly-in/fly-out and fly-over: mining and regional development in Western Australia. The Australian Geographer 32, 133-148. doi: 10.1080/00049180120066616

Taylor, G. T. (1926). The frontiers of settlement in Australia. Geographical Review 16, 1-25. doi: $10.2307 / 208500$ 
Taylor, J. (1998). Measuring short-term population mobility among indigenous Australians: options and implications. The Australian Geographer 29, 125-137. doi: 10.1080/00049189808703207

Taylor, J. (2001). Anangu population dynamics and future growth in the Uluru-Katatjuta National Park. CAEPR Discussion Paper No. 211, Centre for Aboriginal Economic Policy Research. The Australian National University, Canberra.

Taylor, J. (2003). Indigenous Australians: the first transformation. In 'The Transformation of Australia's Population: 1970-2030'. (Eds S. E. Khoo and P. Macdonald.) pp. 17-39. (UNSW Press: Sydney.)

Taylor, J. (2006). Population and diversity: policy implications of emerging indigenous demographic trends. CAEPR Discussion Paper No. 283, Centre for Aboriginal Economic Policy Research. The Australian National University, Canberra.

Taylor, J., and Bell, M. (1996). Mobility among indigenous Australians. In: 'Population shift: Mobility and Change in Australia'. (Eds P. W. Newton and M. Bell.) pp. 392-411. (Australian Government Publishing Service: Canberra.)

Taylor, J., and Bell, M. (2004). Continuity and change in indigenous Australian population mobility. In: 'Population Mobility and Indigenous Peoples in Australasia and North America'. (Eds J. Taylor and M. Bell.) pp. 13-43. (Routledge: New York.)

Taylor, J., and Scambary, B. (2005). 'Indigenous People and the Pilbara Mining Boom: a Baseline for Regional Participation.' (ANU E Press: Canberra.)
Taylor, J., Brown, D., and Bell, M. (2006). Population dynamics and demographic accounting in arid and savanna Australia: methods, issues and outcomes. Desert Knowledge Cooperative Research Centre Research Report No. 16. Desert Knowledge Cooperative Research Centre, Alice Springs, NT.

UNEP (1997). 'World Atlas of Desertification.' (United Nations Environment Programme: London.)

UNEP (2006). 'Global Deserts Outlook.' (United Nations Environment Programme: Nairobi.)

Warchivker, I., Tjapangati, T., and Wakerman, J. (2000). The turmoil of aboriginal enumeration: mobility and service population analysis in a central Australian community. Australian and New Zealand Journal of Public Health 24, 444-449.

Young, E. A. (1990). Aboriginal population mobility and service provisions: a framework for analysis. In 'Hunter-gatherer Demography: Past and Present'. (Eds B. Meehan and N. White.) pp. 186-196 (University of Sydney: Sydney.)

Young, E. A., and Doohan, K. (1989). 'Mobility for survival: a process analysis for aboriginal population movement in central Australia.' North Australia Research Unit, The Australian National University, Darwin, NT.

Zipf, G. K. (1949). 'Human Behaviour and the Principle of Least Effort.' (Addison-Wesley: Reading.)

Manuscript received 15 June 2007; accepted 29 November 2007 